\title{
Spread of COVID-19 in India: A Simple Algebraic Study
}

\author{
Sudipto Roy \\ Department of Physics, St. Xavier's College, Kolkata, West Bengal, India \\ Email: roy.sudipto@sxccal.edu \\ May 10, 2020
}

\begin{abstract}
The number of patients, infected with COVID-19, began to increase very rapidly in India from March 2020. The country was put under lockdown from 25 March 2020. The present study is aimed at providing a simple algebraic analysis of the trend that is evident in the spread of the disease in this part of the world. The purpose of this algebraic approach is to simplify the calculation sufficiently by deviating from the standard techniques that are conventionally used to construct mathematical models of epidemics. The predictions, obtained from this algebraic study, are found to be in reasonable agreement with the recorded data. Using this mathematical formulation we have determined the time variation of the number of asymptomatic patients, who are believed to play a major role in spreading the disease. We have discussed the effect of lockdown in reducing the rate of transmission of the disease. On the basis of the proposed models, predictions have been made regarding the possible trend of the rise in the number of cases beyond the withdrawal of lockdown. All these things have been calculated by using very simple mathematical expressions which can be easily understood and used by those who have a rudimentary knowledge of algebra.
\end{abstract}

Keywords: COVID-19, SARS-CoV-2, Pandemic, India, Social Distancing, Epidemiology, Mathematical Model.

\section{Introduction}

In early December 2019, a cluster of cases of pneumonia had been reported in Wuhan, Hubei province of China. A few days later, the health authorities of that country declared that this cluster was associated with a newly discovered coronavirus (SARS-CoV-2) and the infectious disease caused by it was named coronavirus disease 2019 (COVID-19) by the World Health Organization (WHO) [1,2]. This outbreak of novel coronavirus pneumonia has been declared a public health emergency of international concern by WHO. As of 6:37 pm CEST, 10 May 2020, there have been 3,925,815 confirmed cases of COVID-19, including 274,488 deaths, reported to WHO globally [3]. According to WHO, no pharmaceutical products have yet been shown to be safe and effective for the treatment of COVID-19. Invitro studies have shown that chloroquine, an immune-modulant drug, which has been traditionally used for the treatment of malaria, is effective in reducing viral replication in infections including the SARS-associated coronavirus (CoV) and MERS-CoV [4, 5]. It has been revealed by the current studies that respiratory symptoms of COVID-19 such as fever, dry cough and dyspnea are the most common manifestations, quite similar to severe acute respiratory syndrome (SARS) in 2003 and Middle East respiratory syndrome in 2012 (MERS), which firmly indicates the droplet transmission and contact transmission of the virus. Apart from the typical respiratory disorder, there are less common features like diarrhea, nausea, vomiting, and abdominal discomfort that have been found significantly in different degrees among different study populations [6]. Recent evidences have revealed that

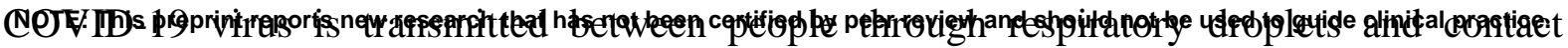


medRxiv preprint doi: https://doi.org/10.1101/2020.05.10.20097691; this version posted May 14, 2020. The copyright holder for this preprint

routes [7-11]. Transmission through droplets takes place when a person is in close contact (within 1 metre) with another person, who has developed respiratory symptoms (coughing or sneezing) due to COVID-19 infection, and is thereby at risk of having his/her mucosae (mouth and nose) or conjunctiva (eyes) exposed to potentially infective respiratory droplets (which are generally known to be greater than 5-10 $\mu \mathrm{m}$ in diameter). Droplet transmission can also occur through fomites in the immediate vicinity around the infected person [12]. Thus, the transmission of the virus that causes COVID-19 can occur by direct contact with an infected person and indirect contact with surfaces in his/her immediate environment or with the objects that have been used on the infected person (e.g. stethoscope or thermometer). Airborne transmission of the virus is not the same as droplet transmission. It is caused by the microbes within droplet nuclei, which are generally like particles less than $5 \mu \mathrm{m}$ in diameter, and which are released by the evaporation of larger droplets or exist within dust particles. These particles may remain in the air for long periods of time and they can be transmitted to persons over distances greater than 1 metre [13].

The first case of COVID-19 infection was reported in India on 30 January 2020. As of 8:00 am IST, 10 May 2020, a total of 62,939 cumulative cases of infection including 41,472 active cases, 19,357 recoveries and 2,109 deaths in the country have been confirmed by the Ministry of Health and Family Welfare [14]. So far, the government has issued necessary guidelines and taken several measures to spread awareness regarding COVID-19 and also to enforce social distancing of its citizens to break the chain of transmission of the disease. On 24 March 2020, a nationwide lockdown was announced for a period from 25 March 2020 to 14 April 2020. On 14 April 2020, this lockdown was extended till 03 May 2020. On 01 May 2020 it was further extended till 17 May 2020.

Chatterjee et al. have carried out a detailed study to accumulate evidence that can guide research activities towards the prevention and control such a pandemic spreading so rapidly in India [15]. In another study, Agarwal et al have elaborately discussed the necessity for a proper medical infrastructure to be built up in India to tackle the flow of patients and to ensure the safety of the healthcare workers [16]. Through a detailed mathematical analysis, Mandal et al have discussed the policies to be implemented to prevent the spread of the virus by community transmission [17]. Some other mathematical models, based on several standard theories, have been constructed to predict the number of infections of COVID-19 in India with sufficient accuracy [18-25]. These models are expected to serve as efficient tools which would certainly help the policy makers of the country, at different levels, to make proper plans to prevent the spread of this disease.

In a previously published article, based on a mathematical model, we showed the effect of imposition of lockdown in reducing the rate of rise in the number of infections [26]. It was a dynamical model which was based on a differential equation that was formulated to find the time variation of the number of asymptomatic patients, from which, the number of symptomatic cases was estimated. In the present study, we have constructed the entire mathematical structure upon a simple algebraic equation. The purpose of choosing this method is to make the article comprehensible to the policy makers of the country who come from various educational backgrounds. The models that are based on calculus lead to very accurate results or predictions but they are sometimes very difficult to understand for those who are not sufficiently trained in mathematics. In most of the cases, the conventional models do not lead to mathematical expressions from which predictions can be made. One needs to do numerical calculations (rather than analytical) to arrive at a prediction. In view of the severity and urgency of the crisis caused by COVID-19 outbreak, mathematical models 
medRxiv preprint doi: https://doi.org/10.1101/2020.05.10.20097691; this version posted May 14, 2020. The copyright holder for this preprint (which was not certified by peer review) is the author/funder, who has granted medRxiv a license to display the preprint in perpetuity.

It is made available under a CC-BY 4.0 International license .

should be created in a simple way so that the can be easily understood, amended or modified if necessary and applied extensively by the persons who are responsible for decision making regarding infrastructural arrangements and also the formulation and implementation of rules to be imposed upon the society to ensure social distancing. The calculations involved in the present study are extremely simple in comparison to the ones where one needs to solve a set of coupled differential equations keeping under consideration various factors connected to the society and the constraints of the actual situations caused by the pandemic and the measures to control it.

In the present article, we have discussed the step by step construction of an algebraic structure that allows one to derive an expression representing the time evolution of the number of asymptomatic patients in the country. Like our previously published article, which was based on calculus, this model has an underlying assumption that, due to the lack of tests in sufficient numbers, the statistics regarding the number of patients infected, as declared by the government, are actually about the number of symptomatic patients. After detection, most of them are put under isolation, during which they are not much capable of spreading the disease to other persons. Therefore, the asymptomatic carriers can be regarded as the main agents of transmission of the virus in the society. The present study is based on three models whose unknown parameters have been determined by fitting these models to the actual data of COVID-19 infections in India. For this purpose we have used the statistics of the number of infected persons in India, during the period from 01 March 2020 to 03 May 2020, obtained from the government sources [14]. Using these three models we have determined the time evolution of the number of infected persons over this period. We have graphically shown the positive impact of the imposition of lockdown throughout the country. The present study makes predictions regarding the number of infected cases beyond 17 May 2020, the date up to which the lockdown will continue as per the last announcement made on 01 May 2020. These models show very clearly that a high degree of social distancing has to be maintained to slow down or prevent the transmission of the disease in the country.

\section{Mathematical Models}

Let $y_{1}$ and $y_{2}$ be the numbers of asymptomatic patients on the first and the second days of the span of time under consideration. We propose to express $y_{2}$ in terms of $y_{1}$ in the following way.

$y_{2}=y_{1}+\alpha_{1} y_{1}-\beta_{1} y_{1}$

In equation (1), $\alpha_{1}$ is the average number of persons who become infected with COVID-19, after coming in close contact with each of these $y_{1}$ carriers of the disease, on the first day. Here $\beta_{1}$ denotes the fraction of $y_{1}$ who have undergone a transformation from asymptomatic to symptomatic modes on the first day. It is assumed in the present model that a patient, after being identified as symptomatic, is put into absolute isolation from the society. It prevents the patient completely from playing any role in the transmission of the disease. It is also assumed that no new asymptomatic or symptomatic carrier has entered the geographical region under consideration, during the entire span of time for which this study has been conducted.

The subscript of $\alpha_{1}$ is connected to the serial number of the day concerned. When a lockdown is imposed, the social mixing pattern changes significantly, resulting in a change in the number of persons coming in contact with an asymptomatic carrier. Let us consider a combination of three consecutive periods, of $d_{1}, d_{2} \& d_{3}$ days respectively, during which we 
medRxiv preprint doi: https://doi.org/10.1101/2020.05.10.20097691; this version posted May 14, 2020. The copyright holder for this preprint (which was not certified by peer review) is the author/funder, who has granted medRxiv a license to display the preprint in perpetuity.

It is made available under a CC-BY 4.0 International license .

have no-lockdown, lockdown and again no-lockdown situations successively in a country. The time dependence of $\alpha_{n}$ (i.e. dependence upon $n$ ), under such situations, can be expressed as,

$\alpha_{n}=f_{1}(n) a+f_{2}(n) b+f_{3}(n) a$

Here, the value of each of these three functions, $f_{1}(n), f_{2}(n)$ and $f_{3}(n)$, is unity over the periods of $d_{1}, d_{2} \& d_{3}$ days respectively, and zero otherwise. Thus, the values of $\alpha_{n}$ would be equal to the constants $a, b$ and again $a$, respectively, during these three periods.

We have $\alpha_{n}=a$ for $1 \leq n \leq d_{1}, \alpha_{n}=b$ for $d_{1}<n \leq d_{2}$ and $\alpha_{n}=a$ for $d_{2}<n \leq d_{3}$.

Here $b$ and $a$ can be regarded, respectively, as the measures of social distancing during lockdown and no-lockdown periods. They decrease as social distancing increases.

Like $\alpha_{1}$, the subscript of $\beta_{1}$ corresponds to the serial number of the day under consideration. Its time dependence is due to an assumption that the number of asymptomatic patients may increase at such a rate that, the fraction of them turning into symptomatic ones on a certain day, cannot have a constant value. One of the three forms of $\beta_{n}$, introduced in the present paper, has been assumed to have a constant value (denoted by $\gamma$ in section 2.3), which might be regarded as a kind of time-average of that fraction.

A generalized version of equation (1) can be expressed as,

$y_{n}=\left(1+\alpha_{n-1}-\beta_{n-1}\right) y_{n-1}$

For $n=2$, one obtains equation (1) from equation (3).

Putting $n=n-1$ in equation (3), one gets,

$y_{n-1}=\left(1+\alpha_{n-2}-\beta_{n-2}\right) y_{n-2}$

Substituting for $y_{n-1}$ in equation (3) from equation (4), one obtains,

$y_{n}=\left(1+\alpha_{n-1}-\beta_{n-1}\right)\left(1+\alpha_{n-2}-\beta_{n-2}\right) y_{n-2}$

Continuing in this fashion, equation (3) can be written as,

$y_{n}=y_{1} \prod_{j=1}^{n-1}\left(1+\alpha_{j}-\beta_{j}\right)$

The number of cases $\left(x_{k}\right)$ that become symptomatic from the asymptomatic type, on the $k^{\text {th }}$ day, is then given by,

$x_{k}=\beta_{k} y_{k}=\beta_{k} y_{1} \prod_{j=1}^{k-1}\left(1+\alpha_{j}-\beta_{j}\right)$

Therefore, the total number of symptomatic cases recorded till the $n^{\text {th }}$ day is given by,

$z_{n}=\sum_{k=1}^{n} x_{k}=y_{1} \sum_{k=1}^{n} \beta_{k} \prod_{j=1}^{k-1}\left(1+\alpha_{j}-\beta_{j}\right)$

In equations (6), (7) and (8) $\alpha_{j}=f_{1}(j) a+f_{2}(j) b+f_{3}(j) a$, as per equation (2). If the third phase is absent we have $\alpha_{j}=f_{1}(j) a+f_{2}(j) b$. There can be many such phases coming one after another. For a process, with $L$ number of such phases, $\alpha_{j}$ is given by, 
$\alpha_{j}=\sum_{m=1}^{L} f_{m}(j) g_{m}$

Here $g_{m}=a$ for the odd values of $m$ and $g_{m}=b$ for the even values of $m$.

Equation (8) actually gives us the value that needs to be compared with the number that is declared by the government as the total number of confirmed COVID-19 cases registered in the country till the $\mathrm{n}^{\text {th }}$ day. It is the cumulative count of asymptomatic cases till that day.

Without any imposition of lockdown, over the entire period under study, we must have $\alpha_{j}=a$, according to equation (2). Equation (8) will then have the following form.

$z_{n}=\sum_{k=1}^{n} x_{k}=y_{1} \sum_{k=1}^{n} \beta_{k} \prod_{j=1}^{k-1}\left(1+a-\beta_{j}\right)$

Relative proportions of the symptomatic and asymptomatic patients, denoted by $P\left(z_{n}\right)$ and $P\left(y_{n}\right)$ respectively, are given by the following two expressions.

$P\left(z_{n}\right)=\frac{z_{n}}{y_{n}+z_{n}}=\frac{\sum_{k=1}^{n} \beta_{k} \prod_{j=1}^{k-1}\left(1+\alpha_{j}-\beta_{j}\right)}{\prod_{j=1}^{n-1}\left(1+\alpha_{j}-\beta_{j}\right)+\sum_{k=1}^{n} \beta_{k} \prod_{j=1}^{k-1}\left(1+\alpha_{j}-\beta_{j}\right)}$

$P\left(y_{n}\right)=\frac{y_{n}}{y_{n}+z_{n}}=\frac{\prod_{j=1}^{n-1}\left(1+\alpha_{j}-\beta_{j}\right)}{\prod_{j=1}^{n-1}\left(1+\alpha_{j}-\beta_{j}\right)+\sum_{k=1}^{n} \beta_{k} \prod_{j=1}^{k-1}\left(1+\alpha_{j}-\beta_{j}\right)}$

$P\left(z_{n}\right)$ and $P\left(y_{n}\right)$ can be expressed in percentages by multiplying their expressions with 100 . As an average estimate one can say that, for each symptomatic case there are $y_{n} / z_{n}$ or $P\left(y_{n}\right) / P\left(z_{n}\right)$ number of asymptomatic cases, which remain mostly undetected in India due to lack of testing facilities.

Combining the numbers of symptomatic and asymptomatic cases, one gets the total number of cumulative infections in the country. Dividing this value by the present population of India $(N)$, one can get the fraction of the population infected with COVID-19. This fraction, denoted by $F_{n}$ here, is given by,

$F_{n}=\frac{y_{n}+z_{n}}{N}=\frac{y_{1}\left[\prod_{j=1}^{n-1}\left(1+\alpha_{j}-\beta_{j}\right)+\sum_{k=1}^{n} \beta_{k} \prod_{j=1}^{k-1}\left(1+\alpha_{j}-\beta_{j}\right)\right]}{N}$

$F_{n}$ can be expressed in percentages by multiplying its expressions with $100 . N=1.36 \times 10^{9}$.

For the present article, we have assumed three functional forms of $\beta_{j}$ described in the following three models.

\subsection{Model-1: Exponential expression for $\boldsymbol{\beta}_{j}$}

Here we assume the following relation for $\beta_{j}$.

$\beta_{j}=\beta_{1} \operatorname{Exp}[\lambda(j-1)]$

In equation (14), $\beta_{1}$ and $\lambda$ are constants. The parameter $\lambda$ determines how fast $\beta_{j}$ changes for any change of $j$. Substituting this $\beta_{j}$ into equations (6), (8) and (10), respectively, we get,

$y_{n}=y_{1} \prod_{j=1}^{n-1}\left(1+\alpha_{j}-\beta_{1} \operatorname{Exp}[\lambda(j-1)]\right)$ 
medRxiv preprint doi: https://doi.org/10.1101/2020.05.10.20097691; this version posted May 14, 2020. The copyright holder for this preprint (which was not certified by peer review) is the author/funder, who has granted medRxiv a license to display the preprint in perpetuity.

$$
\begin{aligned}
& z_{n}=y_{1} \sum_{k=1}^{n} \beta_{1} \operatorname{Exp}[\lambda(k-1)] \prod_{j=1}^{k-1}\left(1+\alpha_{j}-\beta_{1} \operatorname{Exp}[\lambda(j-1)]\right) \\
& z_{n}=y_{1} \sum_{k=1}^{n} \beta_{1} \operatorname{Exp}[\lambda(k-1)] \prod_{j=1}^{k-1}\left(1+a-\beta_{1} \operatorname{Exp}[\lambda(j-1)]\right)
\end{aligned}
$$

\subsection{Model-2: Power law expression for $\beta_{j}$}

Here we assume the following relation for $\beta_{j}$.

$\beta_{j}=\beta_{1} j^{\mu}$

In equation (18), $\beta_{1}$ and $\mu$ are constants. The parameter $\mu$ determines how fast $\beta_{j}$ changes for any change of $j$. Substituting this $\beta_{j}$ into equations (6), (8) and (10), respectively, we get,

$$
\begin{aligned}
& y_{n}=y_{1} \prod_{j=1}^{n-1}\left(1+\alpha_{j}-\beta_{1} j^{\mu}\right) \\
& z_{n}=y_{1} \sum_{k=1}^{n} \beta_{1} k^{\mu} \prod_{j=1}^{k-1}\left(1+\alpha_{j}-\beta_{1} j^{\mu}\right) \\
& z_{n}=y_{1} \sum_{k=1}^{n} \beta_{1} k^{\mu} \prod_{j=1}^{k-1}\left(1+a-\beta_{1} j^{\mu}\right)
\end{aligned}
$$

\subsection{Model-3: A Constant $\boldsymbol{\beta}_{j}$}

Here we consider the following form for $\beta_{j}$.

$\beta_{j}=\gamma$

In equation (22), $\gamma$ is a constant. Substituting this $\beta_{j}$ into equations (6), (8) and (10), respectively, we get,

$$
\begin{aligned}
& y_{n}=y_{1} \prod_{j=1}^{n-1}\left(1+\alpha_{j}-\gamma\right) \\
& z_{n}=y_{1} \sum_{k=1}^{n} \gamma \prod_{j=1}^{k-1}\left(1+\alpha_{j}-\gamma\right) \\
& z_{n}=y_{1} \sum_{k=1}^{n} \gamma(1+a-\gamma)^{k-1}
\end{aligned}
$$

For the present study we have used the following expressions for $f_{1}(n), f_{2}(n)$ and $f_{3}(n)$ respectively, which are required for equations (2) and (9).

$$
\begin{aligned}
& f_{1}(n)=\frac{(1+\tanh \eta n)\left[1+\tanh \eta\left(d_{1}-n\right)\right]}{4} \\
& f_{2}(n)=\frac{\left\{1+\tanh \eta\left(n-d_{1}\right)\right\}\left[1+\tanh \eta\left(d_{1}+d_{2}-n\right)\right]}{4} \\
& f_{3}(n)=\frac{\left\{1+\tanh \eta\left(n-d_{1}-d_{2}\right)\right\}\left[1+\tanh \eta\left(d_{1}+d_{2}+d_{3}-n\right)\right]}{4}
\end{aligned}
$$

According to the definitions of $f_{1}(n), f_{2}(n)$ and $f_{3}(n)$, discussed previously, they must behave like rectangular pulses of unit heights. For this purpose, one must choose the value of the constant $\eta$ to be sufficiently large in comparison to the values of $d_{1}, d_{2}$ and $d_{3}$. 
medRxiv preprint doi: https://doi.org/10.1101/2020.05.10.20097691; this version posted May 14, 2020. The copyright holder for this preprint (which was not certified by peer review) is the author/funder, who has granted medRxiv a license to display the preprint in perpetuity.

It is made available under a CC-BY 4.0 International license .

\section{Graphical Interpretation}

Figure 1 shows the time variation of the number of symptomatic patients $\left(z_{n}\right)$. The black circles represent the data regarding the confirmed COVID-19 cases registered in India from 01 March 2020 (i.e. $n=1$ ) to 03 May 2020 (i.e. $n=64$ ), as obtained from the government sources [14]. The red circles represent the values predicted by Model-1 of the present study. The predictions from the model are in reasonable agreement with the recorded data for a certain set of parameter values which are, $y_{1}=100, a=0.2, b=0.125, \beta_{1}=0.022$ and $\lambda=-0.008$. These values have been used in the present study for Model-1.

Figure 2 shows the time variation of the number of symptomatic patients $\left(z_{n}\right)$. The black circles represent the data regarding the confirmed COVID-19 cases registered in India from 01 March 2020 (i.e. $n=1$ ) to 03 May 2020 (i.e. $n=64$ ), as obtained from the government sources [14]. The red circles represent the values predicted by Model-2 of the present study. The predictions from the model are in reasonable agreement with the recorded data for a certain set of parameter values which are, $y_{1}=100, a=0.2, b=0.118, \beta_{1}=0.03$ and $\mu=-0.1$. These values have been used in the present study for Model-2.

Figure 3 shows the time variation of the number of symptomatic patients $\left(z_{n}\right)$. The black circles represent the data regarding the confirmed COVID-19 cases registered in India from 01 March 2020 (i.e. $n=1$ ) to 03 May 2020 (i.e. $n=64$ ), as obtained from the government sources [14]. The red circles represent the values predicted by Model-3 of the present study. The predictions from the model are in reasonable agreement with the recorded data for a certain set of parameter values which are, $y_{1}=100, a=0.2, b=0.116, \gamma=0.03$. These values have been used in the present study for Model-3.

Figure 4 depicts the time evolution of the number of asymptomatic and symptomatic cases, over the period from 01 March 2020 (i.e. $n=1$ ) to 03 May 2020 (i.e. $n=64$ ), based on Model-1, using the parameter values obtained by fitting this model to the actual data (Fig. 1). Lockdown was in effect from 25 March 2020. The impact of lockdown is evident from the reduction of slope of both curves.

Figure 5 shows the time variation of the number of asymptomatic and symptomatic cases, over the period from 01 March 2020 (i.e. $n=1$ ) to 03 May 2020 (i.e. $n=64$ ), based on Model-2, using the parameter values obtained by fitting this model to the actual data (Fig. 2). Lockdown was in effect from 25 March 2020. The impact of lockdown is evident from the reduction of slope of both curves.

Figure 6 depicts the time evolution of the number of asymptomatic and symptomatic cases, over the period from 01 March 2020 (i.e. $n=1$ ) to 03 May 2020 (i.e. $n=64$ ), based on Model-3, using the parameter values obtained by fitting this model to the actual data (Fig. 3). Lockdown was in effect from 25 March 2020. The impact of lockdown is evident from the reduction of slope of both curves.

Figure 7 shows the variation of the number of symptomatic patients as a function of time, with and without the imposition of lockdown, over the period from 01 March 2020 (i.e. $n=1$ ) to 03 May 2020 (i.e. $n=64$ ), from Model-1, using the parameter values obtained by fitting the model to the actual data (Fig. 1). For the case of no lockdown imposition, we have taken $a=b=0.2$. As per prediction of this model, the number $\left(z_{n}\right)$ would have been nearly 10 
medRxiv preprint doi: https://doi.org/10.1101/2020.05.10.20097691; this version posted May 14, 2020. The copyright holder for this preprint (which was not certified by peer review) is the author/funder, who has granted medRxiv a license to display the preprint in perpetuity.

It is made available under a CC-BY 4.0 International license .

times larger than its recorded value, on the $64^{\text {th }}$ day, if the lockdown had not been in effect from the $25^{\text {th }}$ day onwards.

Figure 8 shows the variation of the number of symptomatic patients as a function of time, with and without the imposition of lockdown, over the period from 01 March 2020 (i.e. $n=1$ ) to 03 May 2020 (i.e. $n=64$ ), from Model-2, using the parameter values obtained by fitting the model to the actual data (Fig. 2). For the case of no lockdown imposition, we have taken $a=b=0.2$. As per prediction of this model, the number $\left(z_{n}\right)$ would have been nearly 10 times larger than its recorded value, on the $64^{\text {th }}$ day, if the lockdown had not been in effect from the $25^{\text {th }}$ day onwards.

Figure 9 shows the variation of the number of symptomatic patients as a function of time, with and without the imposition of lockdown, over the period from 01 March 2020 (i.e. $n=1$ ) to 03 May 2020 (i.e. $n=64$ ), from Model-3, using the parameter values obtained by fitting the model to the actual data (Fig. 3). For the case of no lockdown imposition, we have taken $a=b=0.2$. As per prediction of this model, the number $\left(z_{n}\right)$ would have been nearly 10 times larger than its recorded value, on the $64^{\text {th }}$ day, if the lockdown had not been in effect from the $25^{\text {th }}$ day onwards.

Figure 10 shows the time variation of the number of symptomatic patients, in three phases: 1) pre lockdown, 2) during lockdown, 3) post lockdown, from Model-1, where the lockdown continues till 17 May 2020 (as per the announcement made on 01 may 2020), using the parameter values obtained by fitting the model to the actual data (Fig. 1). It has been assumed here that lockdown won't continue beyond 17 May 2020. Here $n=1$ for 01 March 2020.

Figure 11 shows the time variation of the number of symptomatic patients, in three phases: 1) pre lockdown, 2) during lockdown, 3) post lockdown, from Model-2, where the lockdown continues till 17 May 2020 (as per the announcement made on 01 may 2020), using the parameter values obtained by fitting the model to the actual data (Fig. 2). It has been assumed here that lockdown won't continue beyond 17 May 2020. Here $n=1$ for 01 March 2020 .

Figure 12 shows the time variation of the number of symptomatic patients, in three phases: 1 ) pre lockdown, 2) during lockdown, 3) post lockdown, from Model-3, where the lockdown continues till 17 May 2020 (as per the announcement made on 01 may 2020), using the parameter values obtained by fitting the model to the actual data (Fig. 3). It has been assumed here that lockdown won't continue beyond 17 May 2020. Here $n=1$ for 01 March 2020.

Figure 13 shows the time evolution of the number of asymptomatic patients from Model-1, for three values of the parameter $b$, over a period of 100 days, where lockdown continues from the $25^{\text {th }}$ day onwards. These three values of $b$ are smaller than the value obtained by fitting this model to the recorded data (Fig. 1). A smaller value of $b$ means greater degree of strictness in enforcing the lockdown. This figure shows that, for a sufficiently small value of $b, y_{n}$ starts decreasing just after the imposition of lockdown.

Figure 14 shows the time evolution of the number of symptomatic patients from Model-1, for three values of the parameter $b$, over a period of 100 days, where lockdown continues from the $25^{\text {th }}$ day onwards. These three values of $b$ are smaller than the value obtained by fitting this model to the recorded data (Fig. 1). A smaller value of $b$ means a greater degree of social distancing in the lockdown. This figure shows that, for a sufficiently small value of $b$, the slope of $z_{n}$ starts decreasing just after the imposition of lockdown, approaching gradually a 
medRxiv preprint doi: https://doi.org/10.1101/2020.05.10.20097691; this version posted May 14, 2020. The copyright holder for this preprint (which was not certified by peer review) is the author/funder, who has granted medRxiv a license to display the preprint in perpetuity.

It is made available under a CC-BY 4.0 International license .

constant value of $z_{n}$. A constant value of $z_{n}$ means no new cases of symptomatic patients are reported.

Figure 15 shows the time evolution of the number of asymptomatic patients from Model-2, for three values of the parameter $b$, over a period of 100 days, where lockdown continues from the $25^{\text {th }}$ day onwards. These three values of $b$ are smaller than the value obtained by fitting this model to the recorded data (Fig. 2). A smaller value of $b$ means a greater degree of social distancing in the lockdown. This figure shows that, for a sufficiently small value of $b$, $y_{n}$ starts decreasing just after the imposition of lockdown.

Figure 16 shows the time evolution of the number of symptomatic patients from Model-2, for three values of the parameter $b$, over a period of 100 days, where lockdown continues from the $25^{\text {th }}$ day onwards. These three values of $b$ are smaller than the value obtained by fitting this model to the recorded data (Fig. 2). A smaller value of $b$ means greater degree of strictness in enforcing the lockdown. This figure shows that, for a sufficiently small value of $b$, the slope of $z_{n}$ starts decreasing just after the imposition of lockdown, approaching gradually a constant value of $z_{n}$. A constant value of $z_{n}$ means no new cases of symptomatic patients are reported.

Figure 17 shows the time evolution of the number of asymptomatic patients from Model-3, for three values of the parameter $b$, over a period of 100 days, where lockdown continues from the $25^{\text {th }}$ day onwards. These three values of $b$ are smaller than the value obtained by fitting this model to the recorded data (Fig. 3). A smaller value of $b$ means a greater degree of social distancing in the lockdown. This figure shows that, for a sufficiently small value of $b$, $y_{n}$ starts decreasing just after the imposition of lockdown.

Figure 18 shows the time evolution of the number of symptomatic patients from Model-3, for three values of the parameter $b$, over a period of 100 days, where lockdown continues from the $25^{\text {th }}$ day onwards. These three values of $b$ are smaller than the value obtained by fitting this model to the recorded data (Fig. 3). A smaller value of $b$ means greater degree of strictness in enforcing the lockdown. This figure shows that, for a sufficiently small value of $b$, the slope of $z_{n}$ starts decreasing just after the imposition of lockdown, approaching gradually a constant value of $z_{n}$. A constant value of $z_{n}$ means no new cases of symptomatic patients are reported.

Figure 19 shows the time variation of the relative proportions of asymptomatic (A) and symptomatic (S) patients (expressed as percentage of the total number of patients), based on three models, over a period of 100 days since 01 March 2020 (i.e. $n=1$ ), assuming the lockdown to continue till 17 May 2020 (as per the announcement made on 01 May 2020) and not beyond. The smallest value of the ratio of $\mathrm{A} / \mathrm{S}$ is $3 / 2$. Due to lack of tests in sufficient numbers, the asymptomatic cases mostly remain undetected. Therefore, we may conclude that for every two confirmed cases there are at least three undetected cases in India.

Figure 20 shows the time variation of the percentage of total Indian population infected with COVID-19, with both asymptomatic \& symptomatic modes taken together, over a period of 100 days since 01 March 2020 (i.e. $n=1$ ), assuming the lockdown to continue till 17 May 2020 (as per the announcement made on 01 May 2020) and not beyond. The present population of India is $1.36 \times 10^{9}$. It shows that on the $78^{\text {th }}$ day (17 May 2020 ), about $0.1 \%$ of the entire population can be infected, as per the prediction based on Model-1. A smaller percentage is predicted by the other two models. 


\section{FIGURES}

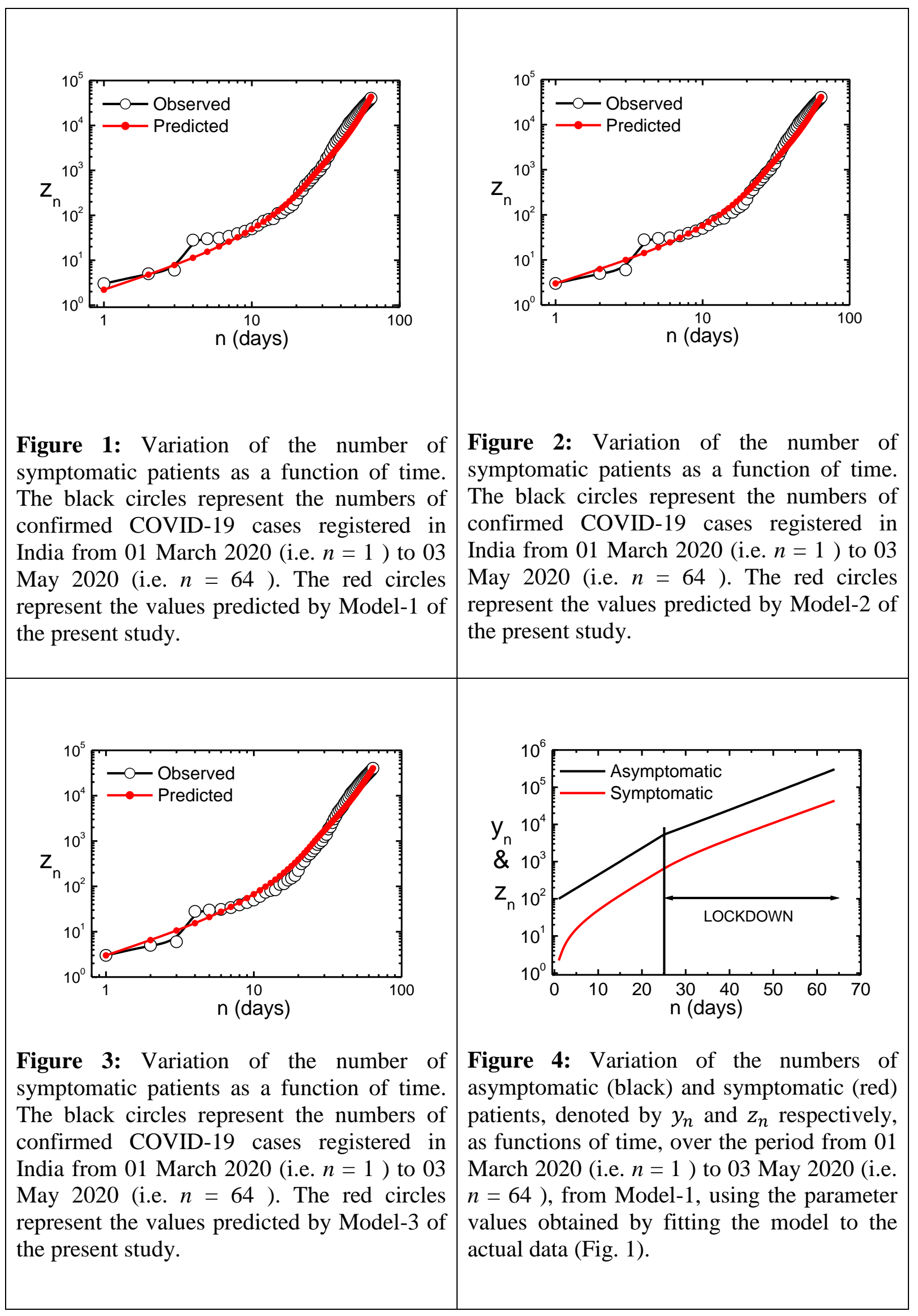




\section{FIGURES}

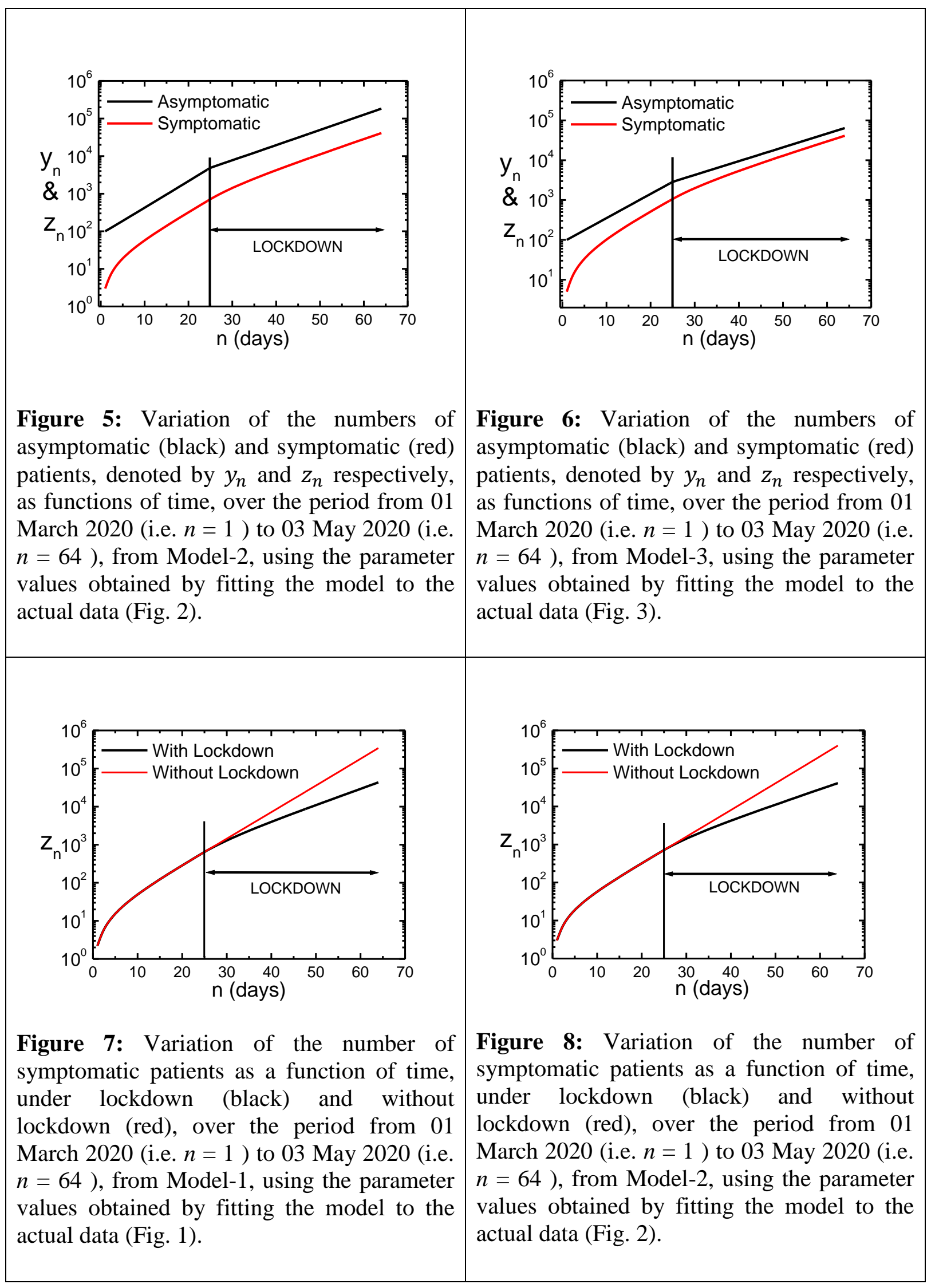


medRxiv preprint doi: https://doi.org/10.1101/2020.05.10.20097691; this version posted May 14, 2020. The copyright holder for this preprint (which was not certified by peer review) is the author/funder, who has granted medRxiv a license to display the preprint in perpetuity.

\section{FIGURES}

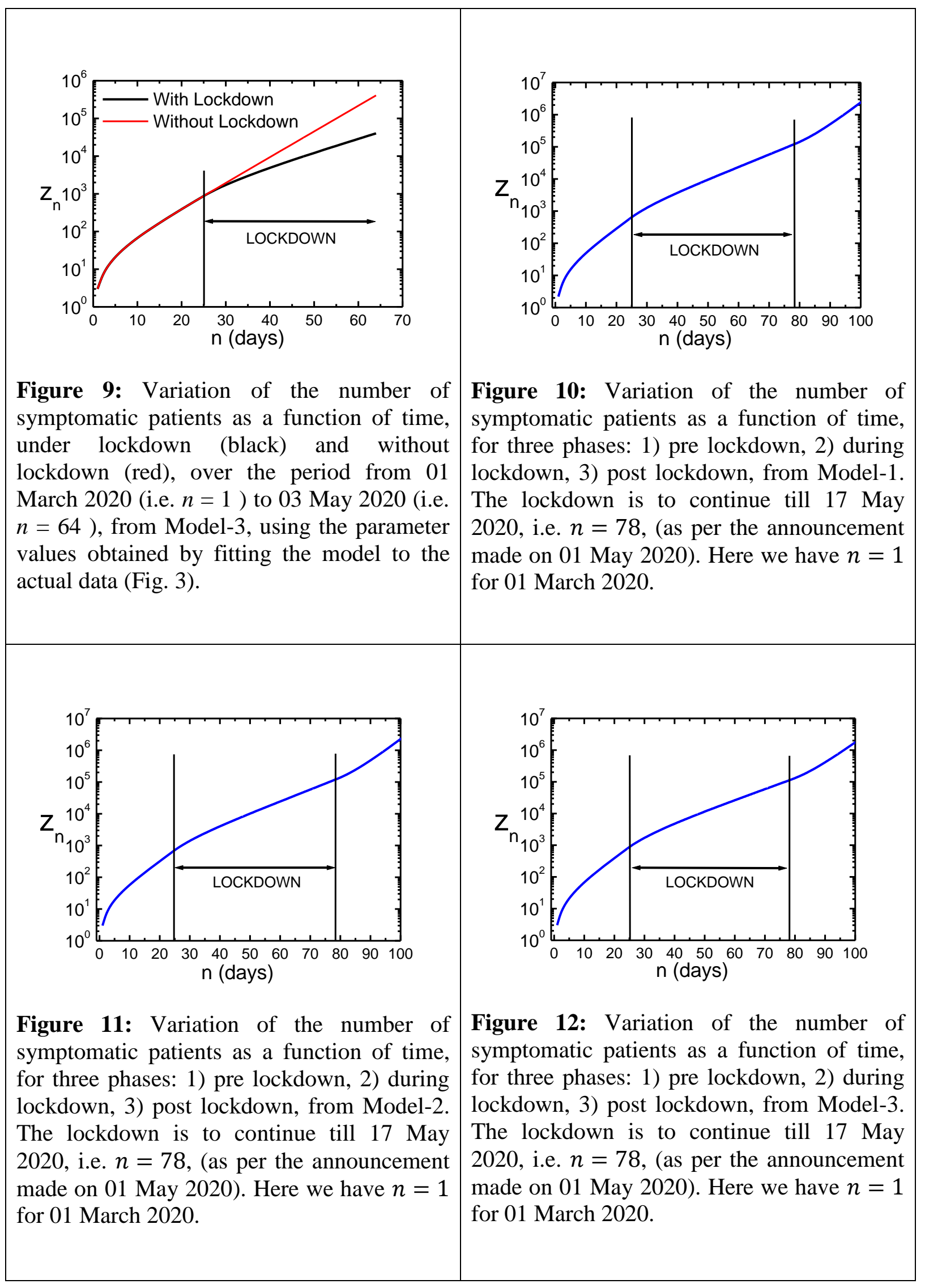


medRxiv preprint doi: https://doi.org/10.1101/2020.05.10.20097691; this version posted May 14, 2020. The copyright holder for this preprint (which was not certified by peer review) is the author/funder, who has granted medRxiv a license to display the preprint in perpetuity.

It is made available under a CC-BY 4.0 International license.

\section{FIGURES}

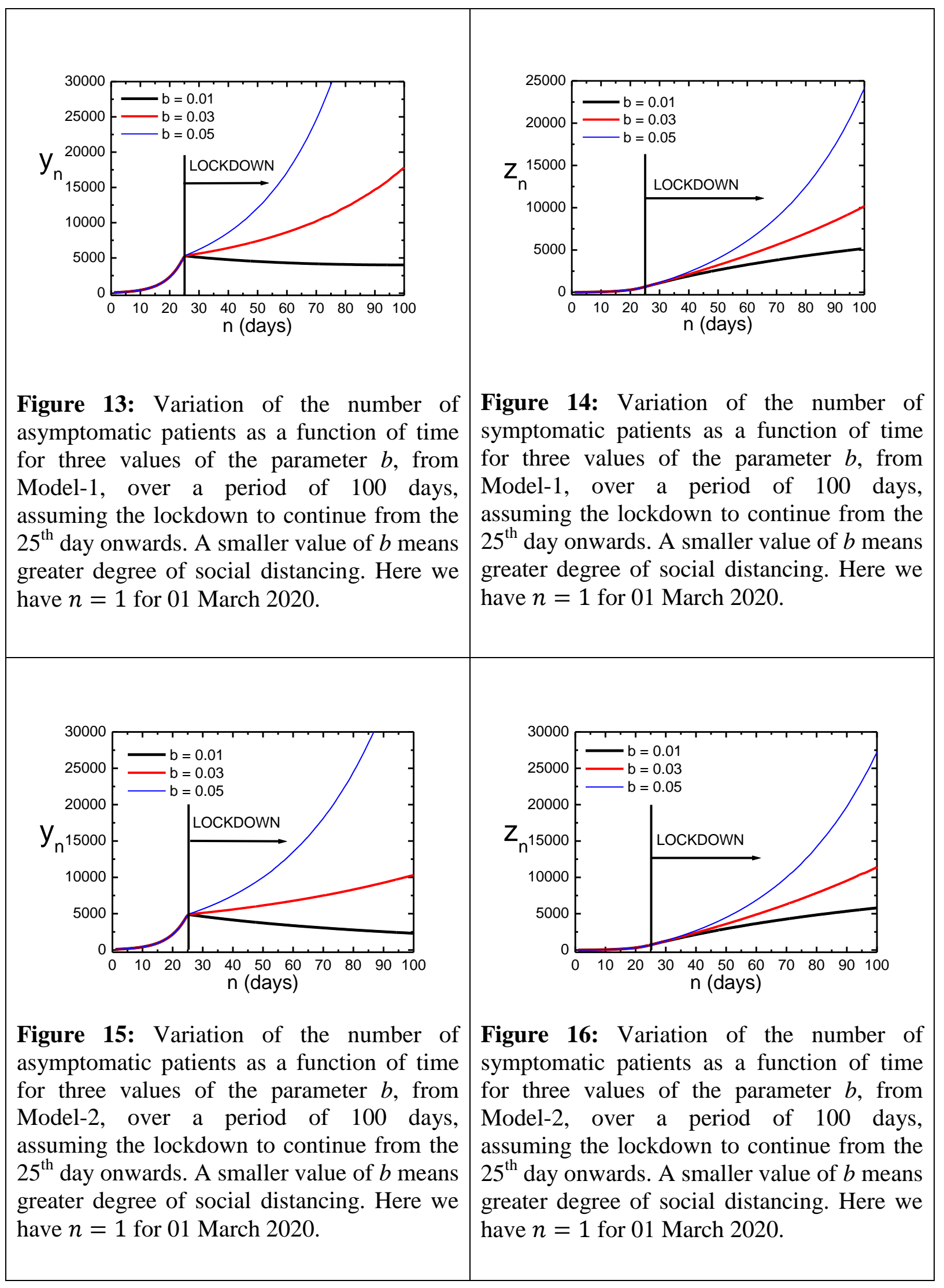


medRxiv preprint doi: https://doi.org/10.1101/2020.05.10.20097691; this version posted May 14, 2020. The copyright holder for this preprint (which was not certified by peer review) is the author/funder, who has granted medRxiv a license to display the preprint in perpetuity.

\section{FIGURES}

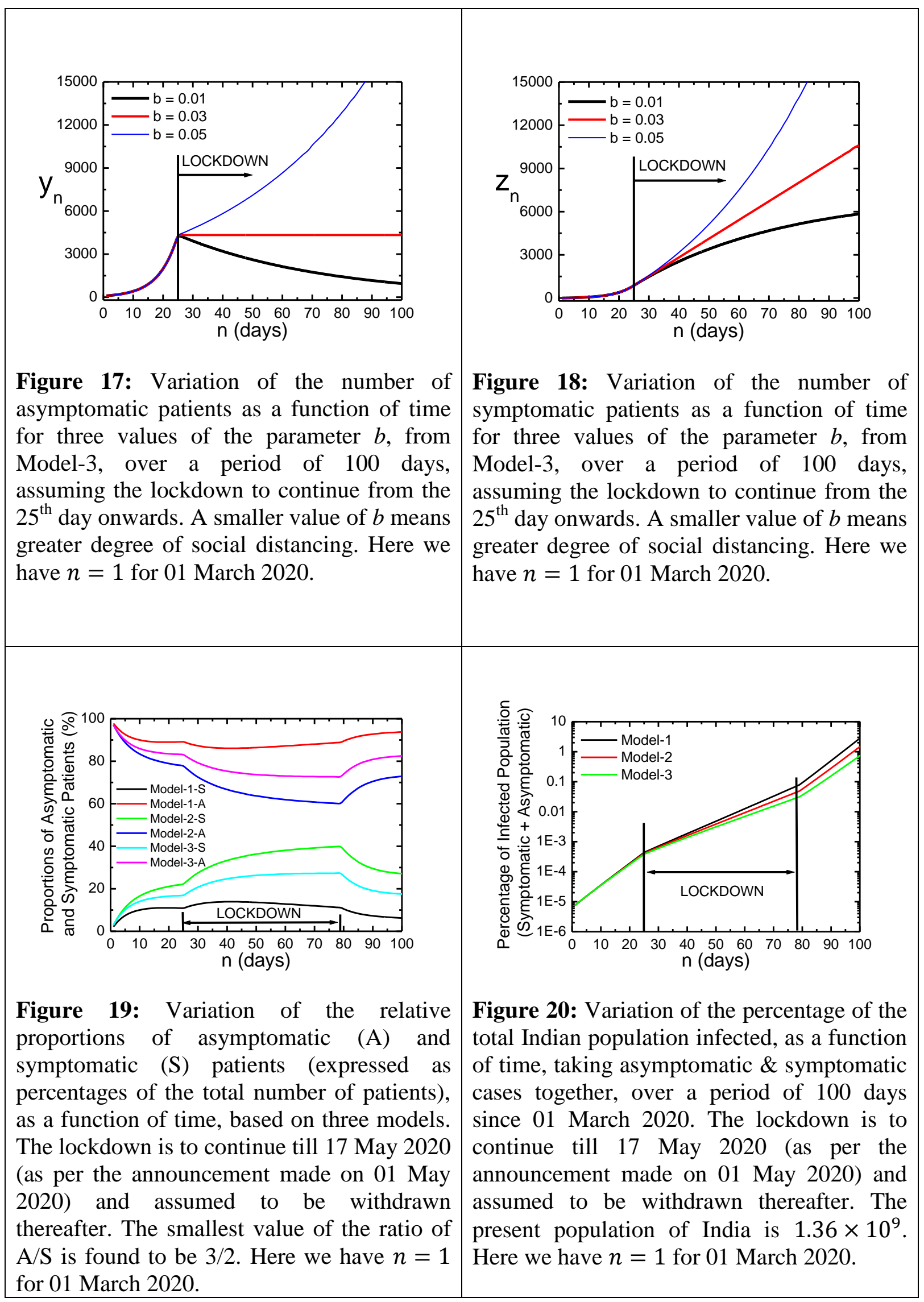


medRxiv preprint doi: https://doi.org/10.1101/2020.05.10.20097691; this version posted May 14, 2020. The copyright holder for this preprint (which was not certified by peer review) is the author/funder, who has granted medRxiv a license to display the preprint in perpetuity.

It is made available under a CC-BY 4.0 International license .

\section{Conclusions}

The present study is based on an assumption that a symptomatic patient is put into complete isolation and thereby he/she is prevented completely from spreading the disease. This cannot be entirely true under the present circumstances. The infection in the body of a person, who has developed some symptoms, can remain undiagnosed mainly due to two reasons. One of the reasons is that some of the symptoms are very much similar to those of other diseases (caused by influenza viruses). The other reason is obviously the lack of testing facilities in the country. This method of algebraic study or prediction can be improved by taking into consideration the role played by the symptomatic patients in the transmission of the disease. Another aspect, which has a plenty of scope for modification, is the functional form of $\beta_{j}$ of equation (6). Apart from the three choices, in this regard, described in the sections 2.1-2.3, there can be many other functions that can represent the time dependence of this parameter. We have chosen the simplest ones. A limitation of this calculation is that the values of the parameters $a$ and $b$, have been assumed to remain constant over the normal (i.e. pre/postlockdown) period and the lockdown period respectively. In reality, the social mixing or distancing patterns may vary frequently with time during a pandemic. In spite of such limitations, the predictions from these models are in reasonable agreement with the actual records, for a certain set of parameter values. Based on this set, the most important finding of the present study is actually a message that social distancing has to be maintained as stringently as possible, which is quite evident from the Figures 13-18. The value of the parameter $b$, which is an indicator of social distancing during lockdown, needs to be sufficiently decreased, to cause $y_{n}$ to fall with time and also to get a flat curve for $z_{n}$.

Conflict of Interest: There is no conflict of interest associated with this article.

Funding Information: No financial assistance has been received for this research.

\section{References}

[1] D. S. Hui et al. The continuing 2019-nCoV epidemic threat of novel coronaviruses to global health -The latest 2019 novel coronavirus outbreak in Wuhan, China. International Journal of Infectious Diseases, 91:264-266, 2020. https://doi.org/10.1016/j.ijid.2020.01.009

[2] J. Yang et al. Prevalence of comorbidities and its effects in patients infected with SARS-CoV-2: a systematic review and meta-analysis. International Journal of Infectious Diseases, 94: 91-95, 2020. https://doi.org/10.1016/j.ijid.2020.03.017

[3] Website of the World Health Organization (WHO). https://www.who.int/

[4] A. Savarino et al. Effects of chloroquine on viral infections: an old drug against today's diseases? THE LANCET Infectious Diseases, 3(11):722-727, 2003. https://doi.org/10.1016/s1473-3099(03)00806-5

[5] P. Colson et al. Chloroquine for the 2019 novel coronavirus SARS-CoV-2. International Journal of Antimicrobial Agents, 55(3):105923, 1-2, 2020. https://doi.org/10.1016/j.ijantimicag.2020.105923 
medRxiv preprint doi: https://doi.org/10.1101/2020.05.10.20097691; this version posted May 14, 2020. The copyright holder for this preprint (which was not certified by peer review) is the author/funder, who has granted medRxiv a license to display the preprint in perpetuity.

It is made available under a CC-BY 4.0 International license .

[6] J. Gu et al. COVID-19: Gastrointestinal Manifestations and Potential Fecal-Oral Transmission, Gastroenterology, 158:1518-1519, 2020. https://doi.org/10.1053/j.gastro.2020.02.054

[7] J. Liu et al. Community Transmission of Severe Acute Respiratory Syndrome Coronavirus 2, Shenzhen, China, 2020. Emerging Infectious Diseases, 26(6), 2020. https://doi.org/10.3201/eid2606.200239

[8] J. F. Chan et al. A familial cluster of pneumonia associated with the 2019 novel coronavirus indicating person-to-person transmission: a study of a family cluster. The Lancet, 395 (10223): 514-523, 2020. https://doi.org/10.1016/S0140-6736(20)30154-9

[9] Q. Li et al. Early Transmission Dynamics in Wuhan, China, of Novel CoronavirusInfected Pneumonia. The New England Journal of Medicine, 382:1199-1207, 2020. https://doi.org/10.1056/NEJMoa2001316

[10] C. Huang et al. Clinical features of patients infected with 2019 novel coronavirus in Wuhan, China. The Lancet, 395(10223):497-506, 2020. https://doi.org/10.1016/S0140-6736(20)30183-5

[11] R. M. Burke et al. Active Monitoring of Persons Exposed to Patients with Confirmed COVID-19 - United States. Morbidity and Mortality Weekly Report, 69(9):245-246, 2020. https://doi.org/10.15585/mmwr.mm6909e1

[12] S. W. X. Ong et al. Air, Surface Environmental, and Personal Protective Equipment Contamination by Severe Acute Respiratory Syndrome Coronavirus 2 (SARS-CoV-2) From a Symptomatic Patient. Journal of the American Medical Association, 323(16): 1610-1612, 2020. https://doi.org/10.1001/jama.2020.3227

[13] Scientific Brief, Published by the World Health Organization (WHO). Title: Modes of transmission of virus causing COVID-19: implications for IPC precaution recommendations. Published on 29 March 2020.

WHO reference number: WHO/2019-nCoV/Sci_Brief/Transmission_modes/2020.2 Available online at: https://www.who.int/news-room/commentaries/detail/modes-oftransmission-of-virus-causing-covid-19-implications-for-ipc-precautionrecommendations

[14] Website of the Ministry of Health and Family Welfare, Government of India. https://www.mohfw.gov.in/

[15] P Chatterjee et al. The 2019 novel coronavirus disease (COVID-19) pandemic: A review of the current evidence. Indian Journal of Medical Research, 151(2): 147-159, 2020. https://doi.org/ 10.4103/ijmr.IJMR_519_20 
medRxiv preprint doi: https://doi.org/10.1101/2020.05.10.20097691; this version posted May 14, 2020. The copyright holder for this preprint (which was not certified by peer review) is the author/funder, who has granted medRxiv a license to display the preprint in perpetuity.

It is made available under a CC-BY 4.0 International license .

[16] A Agarwal et al. Guidance for building a dedicated health facility to contain the spread of the 2019 novel coronavirus outbreak. Indian Journal of Medical Research, 151(2): 177-183, 2020.

https://doi.org/ 10.4103/ijmr.IJMR_518_20

[17] S Mandal et al. Prudent public health intervention strategies to control the coronavirus disease 2019 transmission in India: A mathematical model-based approach. Indian Journal of Medical Research, 151(2): 190-199, 2020.

https://doi.org/10.4103/ijmr.IJMR_504_20

[18] D. Biswas and S. Roy. Analyzing COVID-19 pandemic with a new growth model for population ecology. (A preprint from $w w w . r e s e a r c h g a t e . n e t)$

https://doi.org/10.13140/RG.2.2.34847.92324/1

[19] Arti M. K. and K. Bhatnagar. Modeling and Predictions for COVID 19 Spread in India. (A preprint from www.researchgate.net).

https://doi.org/10.13140/RG.2.2.11427.81444

[20] T. Kaur et al. Anticipating the novel coronavirus disease (COVID-19) pandemic. (A preprint from $w w w . m e d r x i v . o r g$ )

https://doi.org/10.1101/2020.04.08.20057430

[21] S. Mukhopadhyay and D. Chakraborty. Estimation of undetected COVID-19 infections in India. (A preprint from www.medrxiv.org)

https://doi.org/10.1101/2020.04.20.20072892

[22] A. Rajesh et al. COVID-19 prediction for India from the existing data and SIR(D) model study. (A preprint from www.medrxiv.org)

https://doi.org/10.1101/2020.05.05.20085902

[23] R. Ranjan. Predictions for COVID-19 Outbreak in India Using Epidemiological Models.

(A preprint from www.medrxiv.org)

https://doi.org/10.1101/2020.04.02.20051466

[24] S. Ghosh. Predictive Model with Analysis of the Initial Spread of

COVID-19 in India.

(A preprint from www.medrxiv.org)

https://doi.org/10.1101/2020.05.02.20088997

[25] M. Bhatnagar. COVID-19: Mathematical Modeling and Predictions.

(A preprint from $w w w$.researchgate.net).

https://doi.org/10.13140/RG.2.2.29541.96488

[26] S. Roy and K. Roy Bhattacharya. Spread of COVID-19 in India: A Mathematical Model. Journal of Science and Technology, 5(3): 41-47, 2000.

https://doi.org/10.46243/jst.2020.v5.i3.pp41-47 